\title{
REPRESENTASI MAKROSKOPIK DAN SIMBOLIK UNTUK MEMAHAMI GAYA ANTARMOLEKUL PADA KROMATOGRAFI LAPIS TIPIS
}

\section{MACROSCOPIC AND SYMBOLIC REPRESENTATION FOR UNDERSTANDING OF INTERMOLECULAR FORCES IN THIN LAYER CHROMATOGRAPHY}

\author{
Sukib* dan Muti’ah \\ Program Studi Pendidikan Kimia FKIP Universitas Mataram, Mataram, Indonesia \\ Email: $\underline{\text { sukib64@yahoo.com }}$
}

Diterima: 15 Mei 2020. Disetujui: 14 Mei 2020. Dipublikasikan: 29 Juni 2020

\begin{abstract}
Abstrak: Tujuan dari penelitian ini adalah untuk mengetahui hubungan antara penguasaan konsep gaya antarmolekul dengan konsep kromatografi lapis tipis KLT baik sebelum maupun sesudah pembelajaran menggunakan fenomena multi-level. Sebanyak 30 mahasiswa peserta kuliah pemisahan kimia digunakan sebagai sampel Pengambilan data dilakuan dengan cara tes tertulis. Langkah penelitian meliputi: identifikasi miskonsepsi tentang gaya antarmolekul dan konsep KLT, penerapan pembelajaran menggunakan fenomena multi-level, dan tes akhir tentang pemahaman gaya antar-molekul dalam KLT. Hasil penelitian menunjukan bahwa: (1) miskonsepsi mahasiswa pada konsep gaya antarmolekul adalah hal membedakan gaya antarmolekul dan intra-molekul, kekuatan relatif gaya antarmolekul, pengertian dan mekanisme terjadinya gaya London, (2) Miskonsepsi pada konsep KLT meliputi interaksi molekuler yang terjadi pada saat pemisahan, faktor penyebab perbedaan pergerakan analit, (3) Secara statistik terdapat hubungan yang tinggi antara penguasaan konsep gaya antar molekul dengan pemahaman KLT, (4) Penerapan fenomena submikroskopis, simbolik, dan makroskopis mampu meningkatkan pemahaman siswa pada konsep gaya antarmolekul pada KLT
\end{abstract}

Kata kunci: Representasi makroskopik, simbolik, gaya antarmolekul, KLT

\begin{abstract}
The purpose of this study was to determine the relationship between understanding of intermolecular forces with thin layer chromatography concept both before and after learning using the multiple levels of representation. The subjects were 30 students participating in chemical separation lectures. The data were obtained through evaluation tests. The research steps include: identification of misconceptions about intermolecular forces and the TLC concept, application of learning using multiple levels of representation, and final tests on understanding intermolecular forces in TLC. The results showed that: (1) students' misconceptions on the intermolecular forces concept are distinguishing between intermolecular and intramolecular forces, the relative strength of intermolecular forces, understanding and mechanisms of the London force, (2) Misconceptions on the TLC concept include molecular interactions that occur when separation, factors affecting of differences in analytes 'movements, (3) Statistically there is a high relationship between understanding of intermolecular force concepts and understanding of TLC, (4) Application of submicroscopic, symbolic, and macroscopic phenomena can increase students' understanding of the concept of intermolecular forces on TLC
\end{abstract}

Keywords: macroscopic, symbolic representation, intermolecular forces, TLC

\section{PENDAHULUAN}

Kromatografi merupakan materi utama pada matakuliah pemisahan kimia tingkat sarjana [1]. Kajian kromatografi mencakup kromatografi lapis tipis, kroma-tografi kolom, kromatografi gas, dan kromatografi cair kinerja tinggi. Kromatografi lapis tipis KLT atau lebih dikenal TLC (thin layer choramatography) merupakan topik yang penting bagi mahasiswa, karena menjadi dasar dalam memahami jenis kromatografi lainya[2][3]

Kromatografi lapis tipis juga menjadi teknik deteksi secara cepat untuk analisis senyawa dalam suatu sampel bahan alam [4]. Itulah sebabnya Dickson dan kawan-kawan menyatakan bahwa kromatografi lapis tipis merupakan "mata" bagi seorang kimiawan organik [5]. Namun demikian dari hasil pengalaman mengajar menunjukan bahwa mahasiswa mengalami kesulitan dalam analisis secara KLT terutama untuk mendapatkan hasil pemisahan yang optimum.

Secara nyata kesulitan mahasiswa terutaman dalam memilih fasa gerak (eluen) dan jenis fasa diam. Mahasiswa terbiasa dengan mengacu pada literatur yang tidak sesuai dengan kondisi percobaan atau memilih eluen dengan coba-coba. Akibatnya hasil yang diperoleh tidak optimal dan banyak membuang bahan kimia. Dari hasil kajian literatur dapat terungkap bahwa hal tersebut disebabkan mahasiswa tidak memiliki konsep dasar mekanisme terjadinya pemisahan. [6], [7], [8], [9]

Menurut Keer dan kawan-kawan kromatografi adalah teknik analisis untuk memisahkan senyawa-senyawa dalam suatu 
campuran berdasarkan interaksinya dengan fasa diam dan fasa gerak [10]. Hal tersebut menunjukan bahwa konsep dasar dari teknik kromatografi adalah gaya antarmolekul (intermolecular forces) suatu senyawa [11]. Namun demikian dari hasil penelitian terdahulu menunjukan bahwa sebagian besar siswa mengalami kesulitan dalam memahami konsep gaya intermolekul ([12],[13],[14,[15],[16]

Beberapa peneliti telah melakukan inovasi pembelajaran pada gaya intermolekul, misalnya pembelajaran berbasis laboratorium [17], prinsip destilasi [12],[4], pemodelan molekul [16], dan simulasi dinamika molekular [18]. Sampai saat ini publikasi mengenai hubungan antara gaya antarmolekul (intermolecular forces) dengan proses pemisahan pada kromatografi lapis tipis belum banyak ditemukan. Prinsip pemisahan dalam kromatografi yang melibatkan gaya antarmolekul mengandung tiga fenomena kimia, yaitu submikroskopis, simbolik, dan makroskopis. Oleh karena itu pembelajaran yang tepat adalah yang mampu melibatkan ke tiga fenomena kimia tersebut [19], [20]. Publikasi ini membahas tentang: miskonsepsi mahasiswa pada konsep gaya intermolekul dan konsep KLT, pembelajaran menggunakan fenomena mikroskopis, simbolik, dan makroskopis untuk menjelaskan proses pemisahan dalam kromatografi lapis tipis.

\section{METODE PENELITIAN} Sampel

Sampel dalam penelitian ini adalah Mahasiswa semester 4, Program Studi Pendidikan Kimia, FKIP Unram yang sedang mengikuti kuliah pemisahan kimia dengan topik kromatografi lapis tipis. Jumlah mahasiswa peserta matakuliah sebanyak 30 orang. Penelitian ini merupakan penelitian deskriptif yang didasarkan pada data kualitatif dan kuantitatif.

\section{Tahapan Penelitian}

Penelitian deskriptif ini diawali dengan analisis miskonsepsi mahasiswa pada konsep gaya antarmolekul (intermolecular forces) dan aplikasinya dalam kromatografi. Pengambilan data dilakukan melalui tes tertulis di pertemuan ke dua. Asumsi pertama mahasiswa telah mendapatkan materi tentang gaya antarmolekul di kimia dasar, ke dua telah mendapatkan materi pendahuluan tentang kromatografi. Hasil tes selanjutnya dianalisis untuk menjadi dasar penerapan metode pembelajaran berikutnya.

Tahapan berikutnya adalah menerapkan pembelajaran yang menggunakan media yang melibatkan fenomena mikroskopis (gejala di tingkat molekuler), simbolik (rumus kimia), dan makroskopis. Media yang digunakan adalah power point yang digabung dengan demonstrasi tentang kromatografi lapis tipis zat warna makanan.

Di akhir pembelajaran mahasiswa di beri tes tertulis tentang proses pemisahan zat warna menggunakan kromatografi lapis tipis. Data kualitatif diperoleh berdasarkan pengamatan aktivitas selama pembelajaran, sedangkan data kuantitatif diperoleh melalui tes tertulis baik tes di awal maupun di akhir pembelajaran.

\section{HASIL DAN PEMBAHASAN \\ Miskonsepsi Mahasiswa pada Konsep Gaya Antarmolekul \\ Publikasi ini akan membahas tentang} konsep gaya antarmolekul sebagai dasar dalam memahami konsep kromatrografi. Oleh karena itu sebagai langkah awal adalah mengidentifikasi tingkat pemahaman mahasiswa pada konsep gaya antarmolakul. Dari hasil analisis jawaban mahasiswa ditemukan bahwa pemahaman mahasiswa masih rendah dengan nilai rata-rata 51. Dari data tersebut menunjukan masih terdapat miskonsepsi mahasiswa pada konsep gaya antarmolekul. Miskonsepsi mahasiswa pada konsep gaya antarmolekul disajikan dalam tabel 1.

Berdasar tabel 1 tersebut menunjukan berbagai jenis miskonsepsi pada konsep gaya antarmolekul, yaitu mengenai perbedaan gaya antarmolekul dan intra-molekul, kekuatan relatif gaya antarmolekul, gaya dispersi London, dan mekanisme terjadinya gaya London. Kesalahan konsep mengenai perbedaan gaya antarmolekul dan intramolekul pertama adalah menggolongkan ikatan hidrogen ke dalam gaya intramolekul. Kesalahan konsep ini terkait adanya jenis ikatan hidrogen intramolekul, misalnya pada molekul hidroksi asam bensoat.

Kesalahan konsep kedua adalah yang menyebutkan bahwa gaya antarmolekul hanyalah gaya van der Waals dan gaya London. Mahasiswa belum memahami adanya gaya lain misalnya ikatan hidrogen, interaksi ion-dipol, dipol-dipol, ion-dipol terinduksi, dan dipol-dipol terinduksi. Hasil penelitian yang diperoleh sesuai dengan hasil penelitian yang disampaikan oleh peneliti terdahulu [16],[21]

Kesalahan pemahaman pada konsep "kekuatan relatif gaya antarmolekul" adalah pernyataan bahwa gaya antar molekul terbesar adalah ikatan hidrogen bukan gaya antara ion-molekul dipol". Mahasiswa menggunakan dasar bahwa ikatan hidrogen sangat berpengaruh pada titik didih senyawa, misalnya pada senyawa HF. Selanjutnya gaya tarik-menarik terendah adalah gaya London, bukan dipol-non dipol. Konsep yang benar adalah gaya dipol-non dipol memiliki gaya tarik menarik paling rendah sebagaimana dinyatakan penulis terdahulu [22], [23], [24], [25]. 
Tabel 1. Miskonsepsi mahasiwa pada gaya antarmolekul

(1) Membedakan gaya intermolekul dan antarmolekul

- Gaya intermolekul bukan hanya ikatan ion dan ikatan kovalen, tetapi termasuk ikatan hidrogen

- Gaya antar molekul hanya gaya van der Waals dan gaya London, tidak menyebutkan: ikatan hidrogen, interaksi ion-dipol, dipol-dipol, ion-dipol terinduksi, dan dipol-dipol terinduksi

(2) Kekuatan gaya antarmolekul

- Gaya tarik antar molekul terbesar adalah ikatan hidrogen, bukan ion-dipol

- Gaya tarik antar molekul terkecil adalah gaya London, bukan dipol-nondipol

(3) Pengertian gaya dispersi London

- Molekul non polar dengan non polar tidak dapat mengalami tarik-menarik

(4) Mekanisme terjadinya gaya London

- Gaya london terjadi akibat terinduksinya elektron suatu atom akibat mendekatnya molekul polar (yang tepat non polar)

(5) Faktor yang mempengaruhi gaya London

- Gaya London dipengaruhi oleh polaritas suatu molekul bukan oleh ukuran molekul.

Alasan mahasiswa yang menyatakan bahwa gaya London memiliki gaya tarik menarik rendah adalah karena gaya London dihasilkan dari molekul nonpolar dengan non polar. Mereka tidak memiliki pengetahuan bahwa gaya Londong dipengaruhi oleh besar kecilnya molekul. Kesalahan konsep mahasiswa tentang gaya London juga beranggapan bahwa molekul nonpolar dengan nonpolar tidak dapat tarik-menarik. Hal ini dikarenakan mahasiswa belum memahami mekanisme terjadinya gaya London. Oleh karena itu mahasiswa yang tidak menjawab pertanyaan mengenai pengertian gaya London juga tidak dapat menjelaskan mekanisme terjadinya gaya London. Hal ini juga sesuai dengan hasil penelitian terdahulu. [12],[13],[14],[15],[26]

Kesalahan mahasiswa mengenai faktor yang mempengaruhi gaya London ditunjukan dengan jawaban bahwa gaya London dipengaruhi oleh polaritas suatu molekul bukan oleh ukuran molekul, struktur, dan jarak antar molekul. Kesalahan tersebut tidak konsisten dengan pernyataan bahwa molekul nonpolar dengan nonpolar tidak mengalami tarik-menarik, tetapi di bagian ini menyatakan bahwa gaya London dipengaruhi polaritas molekul.

\section{Pemahaman Awal Mahasiswa pada Konsep Kromatografi Lapis Tipis}

Pada bagian ini akan dilakukan analisis bagiamana hubungan antara penguasaan konsep gaya antarmolekul dengan penguasan konsep kromatografi lapis tipis KLT. Pada awal pembelajaran ini, yaitu pada saat mahasiswa telah menerima penjelasan umum kromatografi, mahasiswa diberi pertanyaan terkait dengan pemahaman konsep KLT. Dari hasil analisis jawaban mahasiswa dapat dirangkum dalam tabel 2 berikut. Beberapa miskonsepsi mahasiswa pada konsep kromatografi lapis tipis KLT adalah mengenai: prinsip pemisahan zat secara KLT, interaksi antara analit-fasa diam silikagel-fasa gerak butanol, mekanisme pemisahan, dan penerapan pada pemisahan zat warna. Secara umum pemahaman mahasiswa pada prinsip dasar pemisahan secara KLT masih cukup rendah, yaitu sekitar 46. Miskonsepsi pertama adalah pada pemahaman prinsip pemisahan, dimana sebagian mahasiswa menyatakan bahwa pemisahan senyawa didasarkan pada perbedaan massa molekul. Jawaban yang benar adalah didasarkan pada perbedaan polaritas senyawa.

Miskonsepsi ke dua adalah mengenai interaksi molekuler yang terjadi pada saat pemisahan. Sebagian besar mahasiswa menyatakan bahwa interaksi yang terjadi hanya antara analit dan fasa gerak, sebab silikagel merupakan fasa diam. Miskonsepsi ini sesuai dengan hasil penelitian yang dilaporkan oleh peneliti terdahulu. [5], [6],[27]

Miskonsepsi ke tiga mengenai mekanisme pemisahan, yaitu bahwa "pemisahan senyawa analit terjadi akibat persaingan interaksi antara molekul analit dengan molekul fasa gerak". Jawaban yang benar adalah mekanisme terjadi persaingan interaksi antara fasa diam-analit-fasa gerak. Miskonsepsi ke dua adalah pergerakan zat dalam fasa diam tidak dapat diprediksi. Miskonsepsi ke tiga adalah perbedaan pergerakan zat warna makanan disebabkan perbedaan massa molekul zat warna tersebut. Ke tiga jenis miskonsepsi pada mekanisme pergerakan zat/senyawa dalam KLT hampir sama dengan yang ditemukan oleh peneliti terdahulu [8] [6],[27]

Berdasarkan hasil analisis miskonsepsi menunjukan bahwa pemahaman mahasiswa pada konsep gaya antarmolekul dan terapannya pada pemisahan kromatografi lapis tipis KLT masih cukup rendah. Oleh karena itu perlu diterapkan pembelajaran yang mampu merepresentasikan 3 fenomena kimia, yaitu fenomena makroskopis, simbolik dan makroskopis. 
Tabel 2. Pemahaman awal mahasiswa pada kromatografi lapis tipis
(1) Prinsip pemisahan pada KLT
- Pemisahan zat secara kromatografi didasarkan pada perbedaan massa molekul (Mr)
(2) Interaksi molekular yang terjadi pada teknik KLT
- Antara silikagel (fasa diam) dengan butanol (fasa gerak) tidak terjadi gaya tarik menarik/interaksi, karena silikagel merupakan fasa diam, sedangkan butanol fasa gerak
(3) Mekanisme pemisahan pada teknik KLT
- Pemisahan senyawa analit terjadi akibat persaingan interaksi antara molekul analit dengan molekul fasa gerak, tidak dengan fasa diam
- Molekul analit yang berinteraksi kuat dengan molekul fasa diam akan bergerak lebih jauh/lebih cepat
(4) Penerapan KLT pada pemisahan zat warna makanan
- Pada KLT sifat fasa diam silikagel adalah nonpolar
- Pada KLT kita tidak dapat meprediksi mobilitas senyawa dalam fasa diam
- Pergerakan zat warna dalam pemisahan didasarkan bada massa molekul Mr

Pembelajaran Kromatografi Menggunakan Fenomena Multi Level

Untuk dapat menjelaskan gaya antarmolekul dan terapanya pada teknik kromatografi lapis tipis maka telah diterapkan pembelajaran menggunakan media demonstrasi kimia yang dipadukan dengan power point. Pembelajaran dengan metode ini mampu merepresentasikan 3 fenomena kimia tersebut. Fenomena submikroskopis dan simbolik disajika melalui media power point (gambar 3).

Dalam pembelajaran tersebut mahasiswa mengamati gambar yang menunjukan fenomena berbagai gaya antarmolekul baik secara sumbikroskopis maupun simbolik. Dengan menggunakan media tersebut mahasiswa lebih memahami tentang jenis dan perbedaan gaya antarmolekul dan gambaran mikroskopis proses pemisahan dalam KLT.

Untuk memperjelas konsep siswa pada proses pemisahan secara KLT, maka mahasiswa mengikuti kegiatan demonstrasi pemisahan zat warna merah, kuning, dan biru. Setelah mengikuti demonstrasi kimia, selanjutnya foto hasil pemisahan disajikan dalam powerpoint sebagaimana gambar 4 berikut.

Gambar 4 menunjukan fenomena makroskopis dan simbolik proses pemisahan zat warna makanan secara kromatografi lapis tipis. Setelah mahasiswa mengikuti pembelajaran yang menyajikan fenomena makroskopik dan simbolik tentang proses terjadinya pemisahan zat warna secara kromatografi, maka pembelajaran lebih optimal. Dalam hal ini mahasiswa secara jelas dapat memahami gaya antarmolekul dan peranannya pada proses pemisahan secara KLT. Untuk dapat menjelaskan efek pemahaman gaya antarmolekul dan penggunaan fenomena multi level dalam menjelaskan KLT, maka dilakukan analisis kuantitatif.

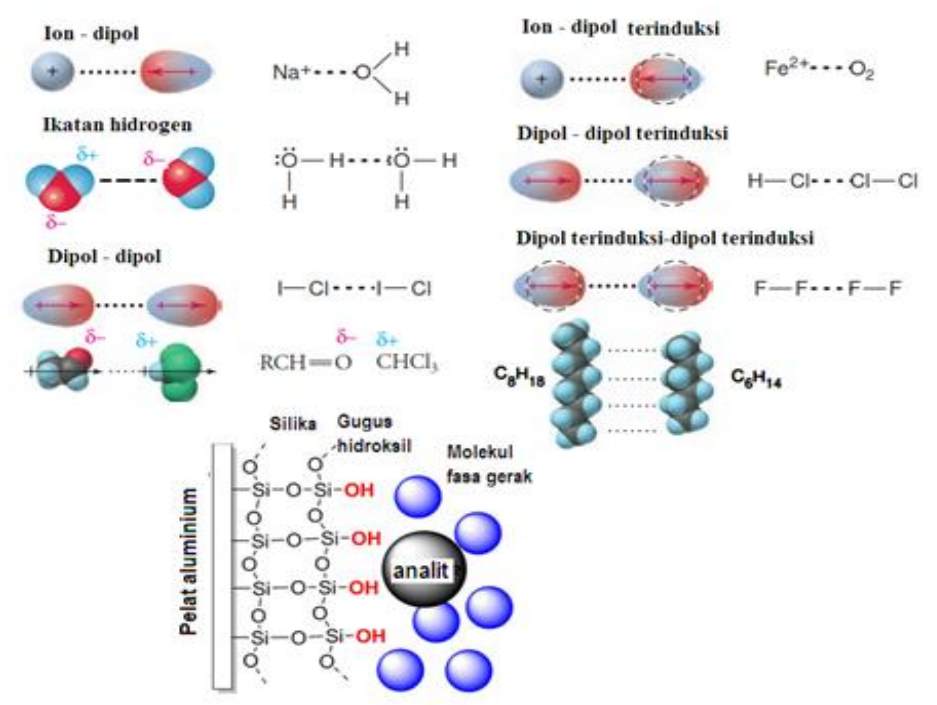

Gambar 3. Fenomena submikrokospis dan simbolik gaya antarmolekul 

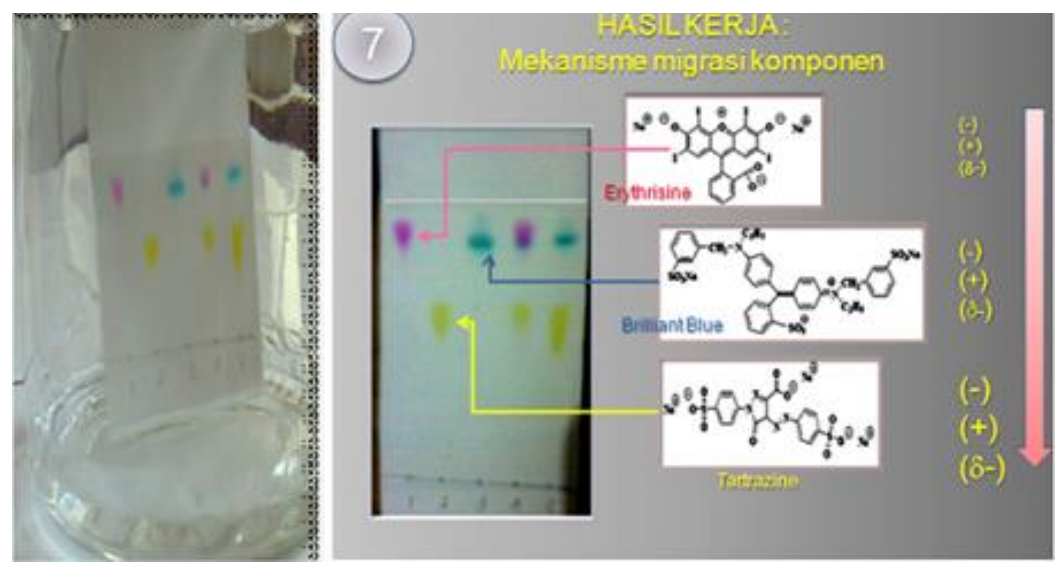

Gambar 4. Fenomena makroskopis dan simbolik proses pemisahan zat warna secara KLT

\section{Efek Penguasaan Konsep Gaya Antarmolekul pada KLT dengan Adanya Media Fenomena Multi Level}

Dari kajian kualitatif di atas, menunjukan ada hubungan antara penguasaan konsep gaya antarmolekul dengan pemahaman kromatografi lapis tipis. Selain itu juga dapat ditunjukan dari aspek kualitatif bahwa pembelajaran yang menggunakan media dengan fenomena multi level dapat memperjelas konsep gaya antarmolekul dan prinsip dasar KLT. Untuk mendapatkan data kuantitatif, maka pada bagian ini akan dijelaskan hubungan antara nilai pemahaman konsep gaya antarmolekul dengan konsep KLT baik sebelum maupun sesudah penerapan media dengan fenomena multi-level sebagaimana gambar 5 berikut.

Berdasarkan gambar tersebut dapat diinformasikan bahwa hubungan antara pemahaman konsep gaya antarmolekul dengan konsep KLT sebelum pembelajaran dinyatakan dalam persamaan: $\mathrm{Y}_{(1)}=0,607 \mathrm{X}+14,95, \mathrm{R}^{2}=$ 0,642 atau $\mathrm{r}=0,801$, dan nilai rata-rata $=46$. Setelah pembelajaran menggunakan fenomena multi level (submikroskopis, simbolik, dan makroskopis) diperoleh persamaan $\mathrm{Y}_{(2)}=0,313 \mathrm{X}+$ $54,74, \mathrm{R}^{2}=0,221$ atau $\mathrm{r}=0,470$ dan nilai rata-rata $=70,7$. Berdasarkan persamaan regresi dan korelasi yang disajikan pada kurva gambar 5 dapat diperoleh informasi sebagai berikut:

(1) Ada hubungan antara kemampuan konsep gaya antarmolekul dengan pemahaman kromatografi lapis tipis. Hal tersebut menunjukan bahwa mahasiswa yang memiliki penguasaan konsep gaya antar- molekul tinggi juga memiliki pemahaman yang tinggi terhadap konsep KLT

(2) Penggunaan media fenomena multi level dapat meningkatkan nilai rata-rata pemahaman KLT dari 46 menjadi 70,7. Hal tersebut menunjukan bahwa pembelajaran menggunakan fenomena multi level dapat meningkatkan pemahaman gaya antarmolekul dan kaitannya dengan prinsip KLT.

(3) Nilai korelasi pada $Y_{(1)}$ (sebelum penerapan media) lebih besar dari pada nilai korelasi pada $\mathrm{Y}_{(2)}$ (setelah penerapan media). Hal tersebut menunjukan bahwa pada $Y_{(1)}$ mahasiswa yang memiliki kemampuan konsep gaya antarmolekul rendah juga memiliki pemahaman KLT rendah dan sebaliknya. Pada $Y_{(2)}$ terjadi hal yang berbeda, yaitu mahasiswa yang memiliki kemampuan konsep gaya molekular rendah, setelah mengikuti pembelajaran maka tingkat pemahaman terhadap konsep KLT dapat meningkat secara signifikan.

Berdasarkan analisis nomor (1) sampai dengan (3) menunjukan bahwa pembelajaran melibatkan fenomena kimia multi level, yaitu fenomena submikroskopis, simbolik, dan makrokospis dapat meningkatkan pemahaman tentang gaya antarmolekul dan hubungannya dengan prinsip pemisahan secara kromatografi lapis tipis. Hasil tersebut dapat dijelaskan dengan mengingat bahwa ilmu kimia mengkaji fenomena nyata (makroskopis), tetapi melibatkan konsepkonsep yang bersifat abstrak (submikroskopis) [19]. Oleh sebab itu dalam menjelaskan konsep kimia perlu menghubungkan ketiga fenomena tersebut. Hal tersebut juga sesuai dengan hasil penelitian terdahulu, bahwa pengggunaan fenomena multi level dalam menjelaskan ilmu kimia dapat meningkatkan pemahaman siswa [19], [27],[28],[30]. 


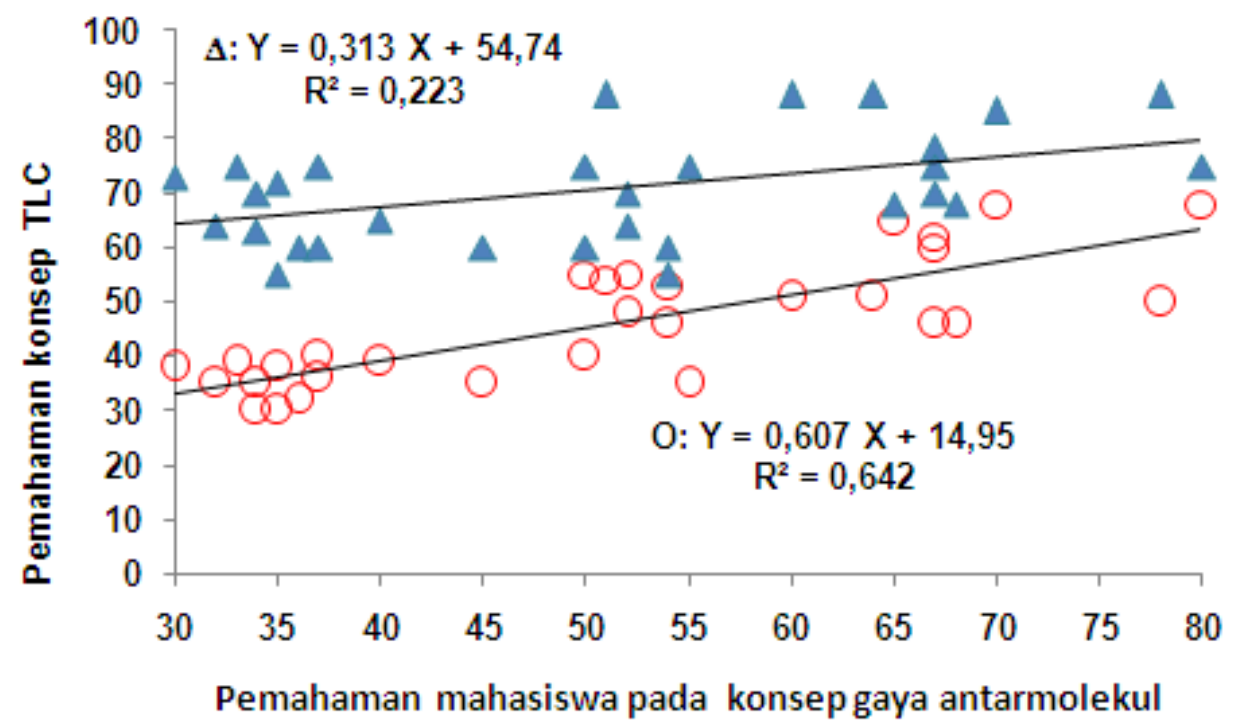

Gambar 5. Kurva hubungan antara kemampuan konsep gaya antar molekul dengan pemahaman kromatografi lapis tipis (KLT)

\section{KESIMPULAN}

Kesimpulan yang diperoleh dalam artikel ini adalah: (1) miskonsepsi mahasiswa pada konsep gaya antarmolekul terletak pada pemahaman tentang perbedaan gaya antarmolekul dan intramolekul, kekuatan relatif gaya antarmolekul, pengertian dan mekanisme terjadinya gaya London, (2) Miskonsepsi pada konsep KLT meliputi interaksi molekuler yang terjadi pada saat pemisahan, faktor yang mempengaruhi pergerakan analit, (3) Secara statistik terdapat hubungan yang tinggi antara penguasaan konsep gaya antar molekul dengan pemahaman KLT, (4) Penerapan fenomena submikroskopis, simbolik, dan makroskopis mampu meningkatkan pemahaman siswa pada konsep gaya pada proses KLT

\section{DAFTAR PUSTAKA}

[1] Haris, D.C. (2010). Quantitative Chemical Analysis $8^{\text {th }}$ ed. W. H. Freeman and Company New York.

[2] Brinkman, U. A. T.; dan De Vries, G. (2015). Small-Scale Thin-Layer Caldwell, B. D.; Zweerink, G. L.; Ducey, M. Separation of Caffeine from Beverages and Analysis Using Thin-Layer Chromatography and Gas Chromatography-Mass Spectrometry. J. Chem. Educ.: 92, 900-902.

[3] Hess, A. V. I. (2007). Digitally Enhanced Thin-Layer Chromatography: An Inexpensive, New Technique for Qualitative and Quantitative Analysis. J. Chem. Educ.: 84, 842-847.

[4] Sjursnes, B. J.; Kvittingen, L.; dan Schmid, R. (2015). Normal and ReversedPhase Thin Layer
Chromatography of Green Leaf Extracts. J. Chem. Educ.: 92, 193-196.

[5] Dickson, H.; Kittredge, K. W.; dan Sarquis, A. M. (2004). Thin-Layer Chromatography: The "Eyes" of the Organic Chemist. J. Chem. Educ.: 81, 1023-1025.

[6] Starkey, R. (1986). Common chromatography misconception. Journal of Chemical Education, 63(6), 514.

[7] Samide, M. J. (2008). Separation anxiety: An in-class game designed to help students discover chromatography. Journal of Chemical Education, 85(11), 1512-1514.

[8] Lim, K., dan Lim, J. M. (2009). Macroscopic chromatography in the classroom. Lab Talk, 53(3), 30-35.

[9] Caldwell, B. D.; Zweerink, G. L.; dan Ducey, M. (2015). Separation of Caffeine from Beverages and Analysis Using Thin-Layer Chromatography and Gas ChromatographyMass Spectrometry. J. Chem. Educ.: 92, 900902.

[10] Kerr, E.; West, C.; dan Kradtap Hartwell, S. (2016). Quantitative KLT Image Analysis of Urinary Creatinine Using Iodine Staining and RGB Values. J. Chromatogr. Sci. : 54, 639-46.

[11] Murthy, P. S. (2006). Molecular handshake: Recognition through weak covalent interactions.Journal of Chemical Education, 83(7), 1010-1013.

[12] Struyf, J. (2011). An analytical approach for relating boiling points of monofunctional organic compounds to intermolecular forces. Journal of Chemical Education, 88, 937-943

[13] Schultz, E. (2005). Simple dynamic models for hydrogen bonding using velcro-polarized 
molecular models. Journal of Chemical Education, 82(3), 401-405.

[14] Schmidt, H.-J., Kaufmann, B., dan Treagust, D. F. (2009). Students' understanding of boiling points and intermolecular forces. Chemistry Education Research and Practice, 10, 265272.

[15] Rompayom, P., Tambunchong, C., Wongyounoi, S., dan Dechsri, P. (2011). Using open-ended questions to diagnose students' understanding of inter- and intramolecular forces. US China Education Review B,1, 1223.

[16] Nyasulu, F., \& Macklin, J. (2006). Intermolecular and intramolecular forces: A general laboratory comparison of hydrogen bonding in maleic and fumaric acids. Journal of Chemical Education, 83(5), 770-773.

[17] Csizmar, C. M., Force, D. A., dan Warner, D. L. (2011). Implementation of gas chromatography and microscale distillation into the general chemistry laboratory curriculum as vehicles for examining intermolecular forces. Journal of Chemical Education, 88, 966-969.

[18] Burcholder, P. R., Purser, G. H., dan Cole, R. S. (2008). Using molecular dynamics simulation to reinforce student understanding of intermolecular forces. Journal of Chemical Education, 85(8), 1071-1077.

[19] Treagust, D. F., Chittleborough, G., dan Mamiala, T. L. (2003). The role of submicroscopic and symbolic representations in chemical explanations. International Journal of Sci-ence Education 25(11), 13531368

[20] Adbo, K. danTaber, K. S. (2009). Learners' mental models of the particle nature of matter: A study of 16-year-old Swedish science students. International Journal of Science Education, 31(6), 757-786.
[21] Tarhan, L., Ayar-Kayali, H., Urek, R. O., dan Acar, B. (2008). Problem-based learning in $9^{\text {th }}$ grade chemistry class: 'intermolecular forces'. Research in Science Education, 38(3), 285300.

[22]Zumdahl, S.S dan Zumdahl, S.A. (2014). Chemistry Sixth Edition, Mary Finch, USA

[23] [23] Jespersen, N.D. dan Brady, J.E. (2012). Chemistry Nine Edition, John Willey \& Sons Incs. USA

[24] Silberberg, M.S., (2010). Principles of General Chemistry Second Edition, McGraw-Hill Inc. New York, USA

[25] Ebbing, D.D. dan Gammon, S.D. (2009). General Chemistry Ninth Edition, Houghton Mifflin Company, Boston, New York.

[26] Person, E. C., Golden, D. R., dan Royce, B. R. 2010. Salting effects as an illustration of the

[27] Smith, C. A., dan Villaescusa, F. W. (2003). Simulating chromatographic separations in the classroom. Journal of Chemical Education, 80(9), 1023-1025.

[28] Chandrasegaran, A. L., Treagust, D. F., dan Mocerino, M. (2008). An evaluation of a teaching intervention to promote students' ability to use multiple levels of representation when describing and explaining che-mical reactions. Rese-arch in Science Edu-cation, 38(2), 237-248.

[29] Chittleborough, G. D., Treagust, D. F., Mamiala, T. L., dan Mocerino, M. (2005). Students' perceptions of the role of models in the process of science and in the process of learning. Research in Science and Technological Education, 23(2), 195-212.

[30] Coll, R. K., dan Taylor, N. (2002). Mental models in chemistry: Senior chemistry students' mental models of chemical bonding. Chemistry Education: Research and Practice in Europe,3(2), 175-184. 